\title{
ANALYSIS OF MULTI-FOCUS GRAY SCALE IMAGE FUSION USING WAVELETS
}

\author{
Shaik Mohammed Waseem ${ }^{1}$, K. Mahammad Imran', Suryakanth.V. Gangashetty ${ }^{3}$ \\ ${ }^{I}$ M. Tech (VLSI), Gokaraju Rangaraju Institute of Engineering \& Technology, Hyderabad, India \\ ${ }^{2}$ M.E. (CESP), Vasavi College of Engineering, Hyderabad, India \\ ${ }^{3}$ Assistant Professor, (LTRC)-International Institute of Information \& Technology, Hyderabad, India
}

\begin{abstract}
Image fusion has been one of the most promising applications in the field of image processing. So far, there are many articles published in this area, explaining various algorithms of image fusion on different image types. In case of image fusion using wavelet transformation, there is always ambiguity in selecting the proper wavelet. Our paper provides a comparative analysis for choosing a proper wavelet for fusing multi-focus gray scale images using discrete wavelet transform and certain fusion rule. For the statistical analysis, the parameters used are Entropy, Standard Deviation (SD), Root Mean Square Error (RMSE) and Correlation Coefficient (CC). The Statistical analysis is done with the consideration that the original clear reference image of the scene is not available.
\end{abstract}

Keywords: multi focus image, image fusion, Discrete Wavelets

\section{INTRODUCTION}

The main objective of image fusion is to combine information from two or more source images of the same scene to obtain an image with relatively more information content than the individual images. Recently, image fusion methods were continuous developed such as Wavelet Transform based fusion [1], Multi resolution based fusion and Spatial Frequency Measurement based fusion [2]. The one popular multi-focus fusion is using the Wavelet Transforms based methods [1]. There is no single wavelet filter, which will always provide the best performance [3]. Since there are many wavelet filters available, each with the different set of basis functions. The choice of wavelet filters is very crucial factor to gain good fusion performance. Therefore, the main purpose of this paper is to investigate the effect of applying different types of wavelet filters belonging to orthogonal and biorthogonal wavelet families with different orders.

The paper is organized as follow. Section II and III, describes the background and the Multi-focus Gray Scale image fusion respectively. Section IV briefs about Wavelets. Section V deals with Results and discussion. Finally, the summary and conclusion is presented in Section VI.

\section{BACKGROUND}

Wavelet Analysis: The wavelet filters are preferred in image fusion because of their distinct properties such as symmetry, orthogonality and smoothness with order of the filter [4]. In this paper, the wavelet filters of different order of two wavelet families are used for statistical analysis. The orthogonal wavelet family filters used is: daubechies $(1,2$, $3,4, \ldots .45)$, coieflets $(1,2,3,4$, and 5$)$, symlets $(2,4, . .8$, ....30), Discrete Meyer wavelet. The biorthogonal wavelet family filters used is: Biorthogonal 1.1, 1.3, 1.5, 2.2, 2.4, 2.6, 2.8, 3.1, 3.3, 3.5, 3.7, 3.9, 4.4, 5.5, 6.8 and Reverse biorthogonal 1.1, 1.3, 1.5, 2.2, 2.4, 2.6, 2.8, 3.1, 3.3, 3.5, 3.7, $3.9,4.4,5.5,6.8$.

Performance Evaluation Metric: The quality of the fused image can be verified by visual and statistical analysis [3]. The visual analysis depends on human observers to assess the quality and is tedious process. The parameters used for statistical analysis along with their description are given in Table 1 .

Table 1: Performance Parameters

\begin{tabular}{|c|c|c|c|}
\hline $\begin{array}{l}\text { Name of } \\
\text { the Metric }\end{array}$ & Formula & $\begin{array}{l}\text { Features/ } \\
\text { Properties }\end{array}$ & $\begin{array}{l}\text { What to } \\
\text { look for } \\
\text { Min/Aax }\end{array}$ \\
\hline Entropy & (i) $\log _{3} h_{x_{y}}(i)$ & $\begin{array}{l}\text { It is used to } \\
\text { measure } \\
\text { the } \\
\text { informatio } \\
n \text { content } \\
\text { of an } \\
\text { image. }\end{array}$ & Maximum \\
\hline $\begin{array}{l}\text { Standard } \\
\text { Deviation }\end{array}$ & $\begin{array}{l}i-i)^{2} h_{s_{f}}(i) \\
p_{r}\end{array}$ & $\begin{array}{l}\text { This metric } \\
\text { is more } \\
\text { efficient in } \\
\text { the } \\
\text { absence of } \\
\text { noise. }\end{array}$ & Maximum \\
\hline $\begin{array}{l}\text { Root Mean } \\
\text { Square } \\
\text { Error }\end{array}$ & 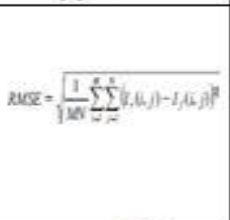 & $\begin{array}{l}\text { Computed } \\
\text { as RMSE of } \\
\text { the } \\
\text { correspond } \\
\text { ing pisels in } \\
\text { the } \\
\text { reference } \\
\text { and the } \\
\text { fused } \\
\text { image. }\end{array}$ & Minimum \\
\hline $\begin{array}{l}\text { Correlation } \\
\text { coefficient }\end{array}$ & 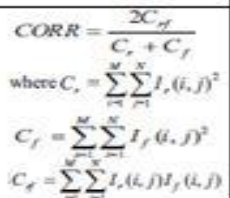 & $\begin{array}{l}\text { It shows } \\
\text { the } \\
\text { correlation } \\
\text { between } \\
\text { the } \\
\text { reference } \\
\text { and fused } \\
\text { inage. }\end{array}$ & Maximum \\
\hline
\end{tabular}




\section{MULTIFOCUS GRAYSCALE IMAGE FUSION}

An image is generally a $2 \mathrm{D}$ projection of $3 \mathrm{D}$ real world object or scene [5]. It is obtained by sensing the light rays reflected from objects of the scene by using image sensors. Multi focus images are the images in which the focus is on specific objects or on specific portions of the entire imaging scene. Since the depth of focus on all objects of the scene is not same in a single image, different images of the same scene having focused on different objects are required [6]. Each of these images has certain important features but is inefficient. A high featured image of the scene is obtained by fusing these multiple images [7]. Grayscale images are simply the images with two intensity levels dark and bright. Combining multiple source images of a scene using specific algorithm to obtain a better quality image is referred to as image fusion.

\section{Algorithm}

\section{Fusing of Multi-Focus Gray Scale Images}

Step 1: Read two or more multi-focus images (We have used multi-focus images which are already registered)

Step 2: Decompose both the input images using Discrete Wavelet Transform with specific wavelet function, to obtain approximation and detail coefficients.

Step 3: Apply 3X3 uniform mask followed by high pass filtering for the detail coefficients (to improve the contrast) of the individual DWT transformed images.

Step 4: Perform averaging of approximation coefficients of both the decomposed images.

Step 5: Compare horizontal, vertical and diagonal detail coefficients of both images and select maximum coefficient by applying absolute maximum rule.

Step 6: Now apply Inverse Wavelet Transform for the obtained approximation and detail coefficients.

Step 7: Display the fused image.

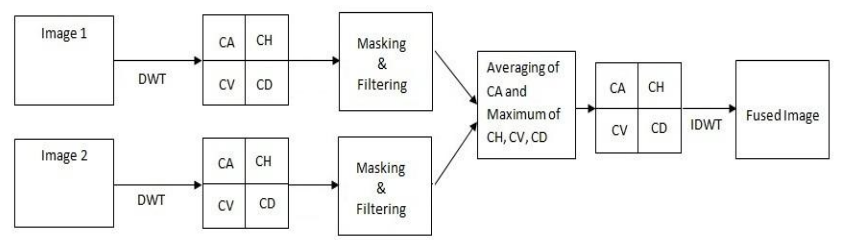

Fig 1: Pictorial representation of the Algorithm

\section{WAVELETS}

Prominence: A wavelet is a small wave that grows and decays essentially in a limited time period. Wavelets are irregular, of limited duration, and often non-symmetrical. They are better at describing anomalies, pulses, and other events that start and stop within the signal. The wavelet function can be designed to have specific properties that are useful in the particular application of the transform [8].It can also be employed to decompose two-dimensional signals (digital image) into different resolution levels for a multi resolution analysis. Besides acting as a microscope to find hidden events in our data, wavelets can also separate the data into various frequency components, as does the FFT [9].

\section{RESULTS AND DISCUSSION}

The performance parameter values obtained for different types of orthogonal and biorthogonal Wavelets of significant order are listed in Table 2 and Table 3. These results are helpful in typical analysis of the respective wavelet filters.

Experimental results show that the order of selection will be Biorthogonal, Reverse Biorthogonal, Symlets, Coiflets, Daubichies wavelets and finally the Meyer wavelet which puts up a poor performance comparatively.

Daubechies wavelets: The daubechies wavelet of order 20 $(\mathrm{db} 20)$ provide higher entropy and the wavelets of higher order (db10 and above) gives better correlation values. The lower order filter $(\mathrm{db} 2)$ gives better standard deviation and RMSE. The statistical results of using daubechies wavelets can be seen in Figure 2.

Symlets: The behavior of symlet filters is approximately similar to that of daubechies wavelets and is shown in Figure 3. In this also, the higher filter order 20 (sym20) gives better entropy compared to other similar wavelet filters with different order and similarly the lower order 2 (sym2) provides better standard deviation. However the RMSE and correlation metrics for both daubechies and symlets shows poor performance compared to other wavelet families.

Coiflets: The lower order coiflet filters (coif1) provides better Standard deviation and less RMSE and the higher order filters (coif4,5) proves to give better entropy and correlation values. The performance parameters obtained using coiflets are shown in Figure 4.

Biorthogonal wavelets: In Figure 5 we can see that the biorthogonal wavelet filter of order 2.2 (bior2.2) gives the best RMSE. The filter of order 5.5 (bior 5.5) gives the best correlation coefficient and better entropy compared to other order biorthogonal filters. The better standard deviation is obtained by the wavelet filter of order 1.1 (bior1.1).

Reverse Biorthogonal wavelets: The Para-metric values obtained using reverse biorthogonal wavelet filters are shown in Figure 6. The filter order 3.1 (rbior 3.1) provides the best standard deviation value compared to all other wavelet families used in the analysis. Entropy is good for filter order 6.8 (rbior 6.8), RMSE is comparatively less for filter order 2.2 (rbior 2.2) and correlation coefficient is better for filter order 1.3 (rbior 1.3).

Discrete Meyer wavelet: The single discrete Meyer wavelet gives better entropy compared to reverse biorthogonal, biorthogonal, coieflets and symlets filters except daubechies filters of higher order. 
Table 2: Orthogonal Wavelets

\begin{tabular}{|l|l|l|l|l|l|l|}
\hline WAVELET & ENTROPY & STD & \multicolumn{2}{l|}{ RMSE } & CORR & \\
\hline Haar or db1 & 7.3260 & 50.9313 & 4.0789 & 4.7525 & 0.9865 & 0.9821 \\
\hline $\mathrm{db} 2$ & 7.3631 & 50.7985 & 4.0091 & 4.7304 & 0.9872 & 0.9824 \\
\hline $\mathrm{db} 10$ & 7.3946 & 50.7195 & 4.0824 & 4.7255 & 0.9874 & 0.9845 \\
\hline $\mathrm{db} 12$ & 7.4120 & 50.6462 & 4.0606 & 4.7583 & 0.9874 & 0.9848 \\
\hline $\mathrm{db} 14$ & 7.4099 & 50.6791 & 4.0712 & 4.6981 & 0.9872 & 0.9850 \\
\hline $\mathrm{db} 20$ & 7.4364 & 50.6456 & 4.0933 & 4.7319 & 0.9874 & 0.9850 \\
\hline & & & & & & \\
\hline sym2 & 7.3631 & 50.7985 & 4.0091 & 4.7304 & 0.9872 & 0.9824 \\
\hline sym4 & 7.3729 & 50.7269 & 4.0002 & 4.6363 & 0.9871 & 0.9848 \\
\hline sym8 & 7.3862 & 50.7100 & 4.0479 & 4.6469 & 0.9871 & 0.9851 \\
\hline sym14 & 7.3995 & 50.6922 & 4.0864 & 4.7220 & 0.9874 & 0.9846 \\
\hline sym18 & 7.3970 & 50.6912 & 4.0790 & 4.6638 & 0.9871 & 0.9852 \\
\hline sym20 & 7.4080 & 50.6785 & 4.0936 & 4.7169 & 0.9873 & 0.9847 \\
\hline & & & & & & \\
\hline coif1 & 7.3476 & 50.7938 & 3.9152 & 4.6272 & 0.9869 & 0.9846 \\
\hline coif2 & 7.3765 & 50.7254 & 3.9849 & 4.6353 & 0.9871 & 0.9850 \\
\hline coif4 & 7.3937 & 50.6985 & 4.0427 & 4.6517 & 0.9871 & 0.9851 \\
\hline coif5 & 7.4005 & 50.6883 & 4.0545 & 4.6596 & 0.9871 & 0.9851 \\
\hline & & & & & & \\
\hline Dmey & 7.4122 & 50.6852 & 4.0931 & 4.6677 & 0.9872 & 0.9851 \\
\hline
\end{tabular}

Table 3: BiOrthogonal Wavelets

\begin{tabular}{|l|l|l|l|l|l|l|}
\hline WAVELET & ENTROPY & STD & \multicolumn{1}{l|}{ RMSE } & CORR & \\
\hline bior1.1 & 7.3260 & 50.9313 & 4.0789 & 4.7525 & 0.9865 & 0.9821 \\
\hline bior1.3 & 7.3567 & 50.7908 & 4.0923 & 4.7385 & 0.9869 & 0.9831 \\
\hline bior1.5 & 7.3641 & 50.7871 & 4.1277 & 4.7189 & 0.9865 & 0.9833 \\
\hline bior2.2 & 7.3622 & 50.8114 & 3.9074 & 4.6231 & 0.9869 & 0.9849 \\
\hline bior2.4 & 7.3777 & 50.7347 & 3.9435 & 4.6407 & 0.9871 & 0.9848 \\
\hline bior2.6 & 7.3848 & 50.7234 & 3.9631 & 4.6413 & 0.9870 & 0.9848 \\
\hline bior2.8 & 7.3856 & 50.7111 & 3.9760 & 4.6461 & 0.9870 & 0.9848 \\
\hline bior3.1 & 7.3469 & 50.6222 & 4.0628 & 4.9359 & 0.9877 & 0.9822 \\
\hline bior3.3 & 7.3798 & 50.7424 & 4.0227 & 4.8481 & 0.9874 & 0.9842 \\
\hline bior3.5 & 7.3759 & 50.6909 & 4.0291 & 4.8327 & 0.9876 & 0.9842 \\
\hline bior3.7 & 7.3658 & 50.6917 & 4.0352 & 4.8179 & 0.9876 & 0.9843 \\
\hline bior3.9 & 7.3678 & 50.6836 & 4.0401 & 4.8106 & 0.9875 & 0.9843 \\
\hline bior4.4 & 7.3801 & 50.7294 & 3.9862 & 4.6446 & 0.9871 & 0.9850 \\
\hline bior5.5 & 7.3914 & 50.7234 & 4.0386 & 4.7533 & 0.9878 & 0.9839 \\
\hline bior6.8 & 7.3844 & 50.7030 & 4.0252 & 4.6545 & 0.9871 & 0.9851 \\
\hline & & & & & & \\
\hline rbio1.1 & 7.3260 & 50.9313 & 4.0789 & 4.7525 & 0.9865 & 0.9821 \\
\hline rbio1.3 & 7.3577 & 50.8122 & 4.0134 & 4.7158 & 0.9876 & 0.9839 \\
\hline rbio1.5 & 7.3586 & 50.7783 & 4.0333 & 4.7046 & 0.9875 & 0.9842 \\
\hline rbio2.2 & 7.3795 & 50.7858 & 3.9331 & 4.6778 & 0.9865 & 0.9840 \\
\hline rbio2.4 & 7.3791 & 50.7487 & 3.9678 & 4.6395 & 0.9869 & 0.9848 \\
\hline rbio2.6 & 7.3838 & 50.7363 & 4.0062 & 4.6395 & 0.9869 & 0.9850 \\
\hline rbio2.8 & 7.3836 & 50.7242 & 4.0232 & 4.6458 & 0.9869 & 0.9851 \\
\hline rbio3.1 & 7.3693 & 50.9758 & 4.6318 & 5.1545 & 0.9794 & 0.9750 \\
\hline rbio3.3 & 7.3806 & 50.7907 & 4.1250 & 4.9652 & 0.9859 & 0.9829 \\
\hline rbio3.5 & 7.3685 & 50.7236 & 4.0709 & 4.8700 & 0.9868 & 0.9838 \\
\hline rbio3.7 & 7.3665 & 50.7069 & 4.0479 & 4.8266 & 0.9871 & 0.9841 \\
\hline rbio3.9 & 7.3681 & 50.6962 & 4.0447 & 4.8107 & 0.9873 & 0.9842 \\
\hline rbio4.4 & 7.3772 & 50.7224 & 3.9813 & 4.6483 & 0.9869 & 0.9847 \\
\hline rbio5.5 & 7.3889 & 50.7562 & 4.0535 & 4.7775 & 0.9871 & 0.9837 \\
\hline rbio6.8 & 7.3988 & 50.6975 & 4.0333 & 4.6535 & 0.9870 & 0.9851 \\
\hline
\end{tabular}



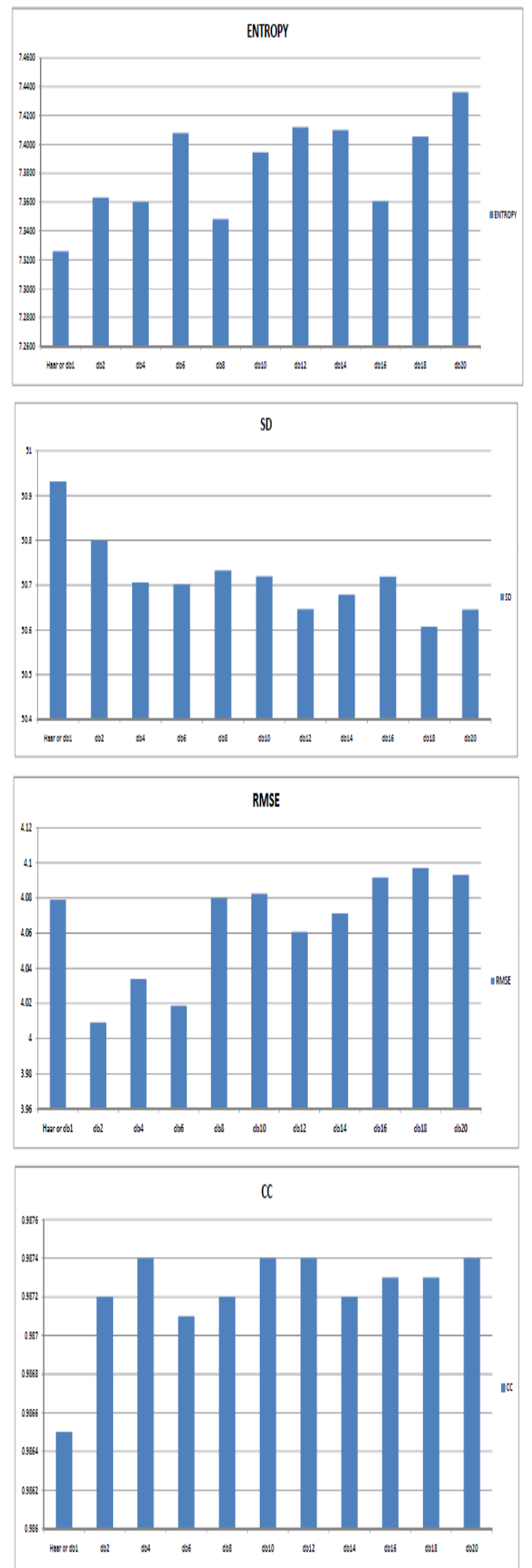

Fig 2: Graphical representation for Daubechies Wavelets
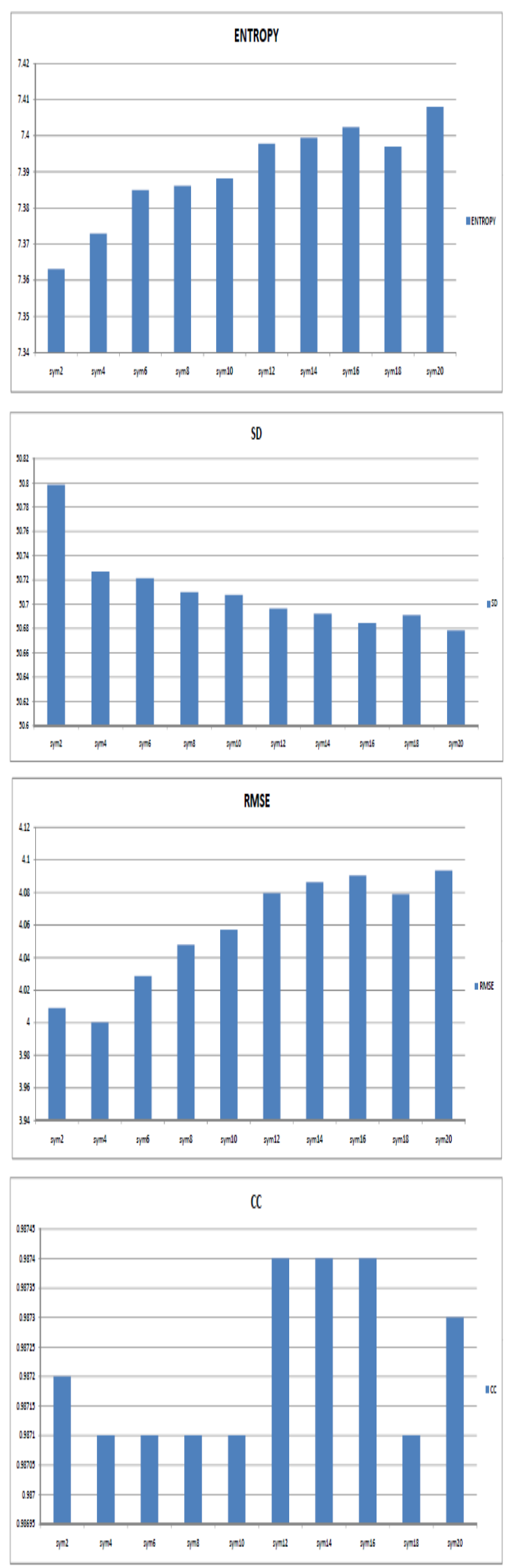

Fig 3: Graphical representation for Symlets 

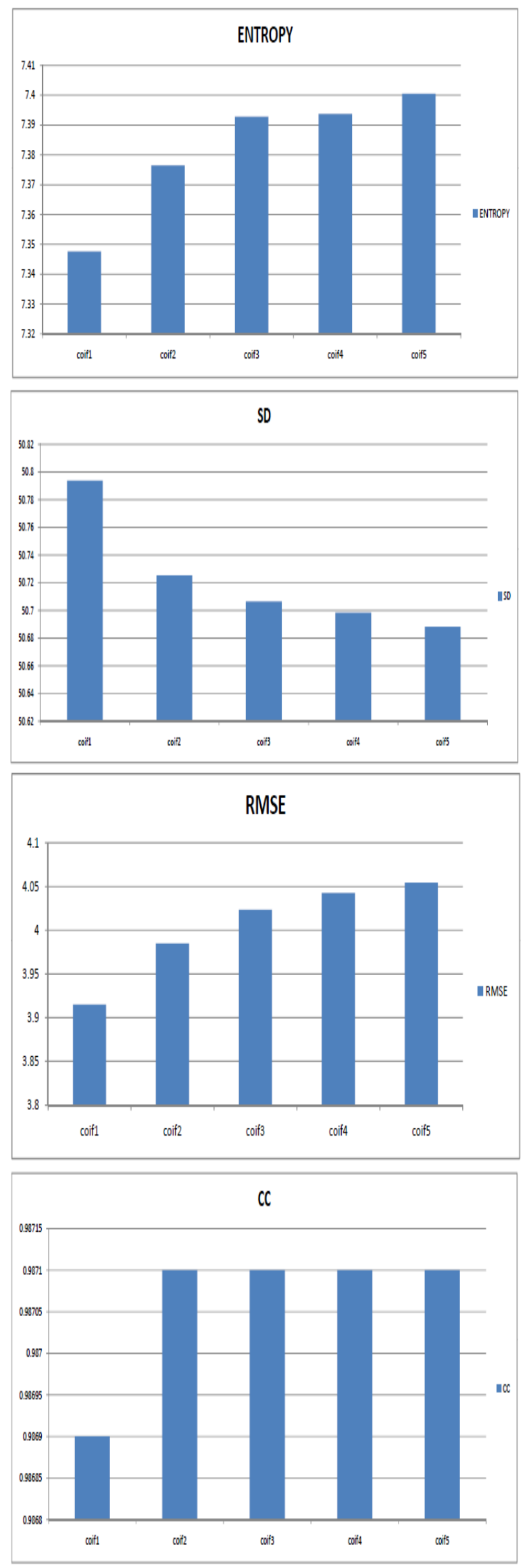

Fig 4: Graphical representation for Coiflets
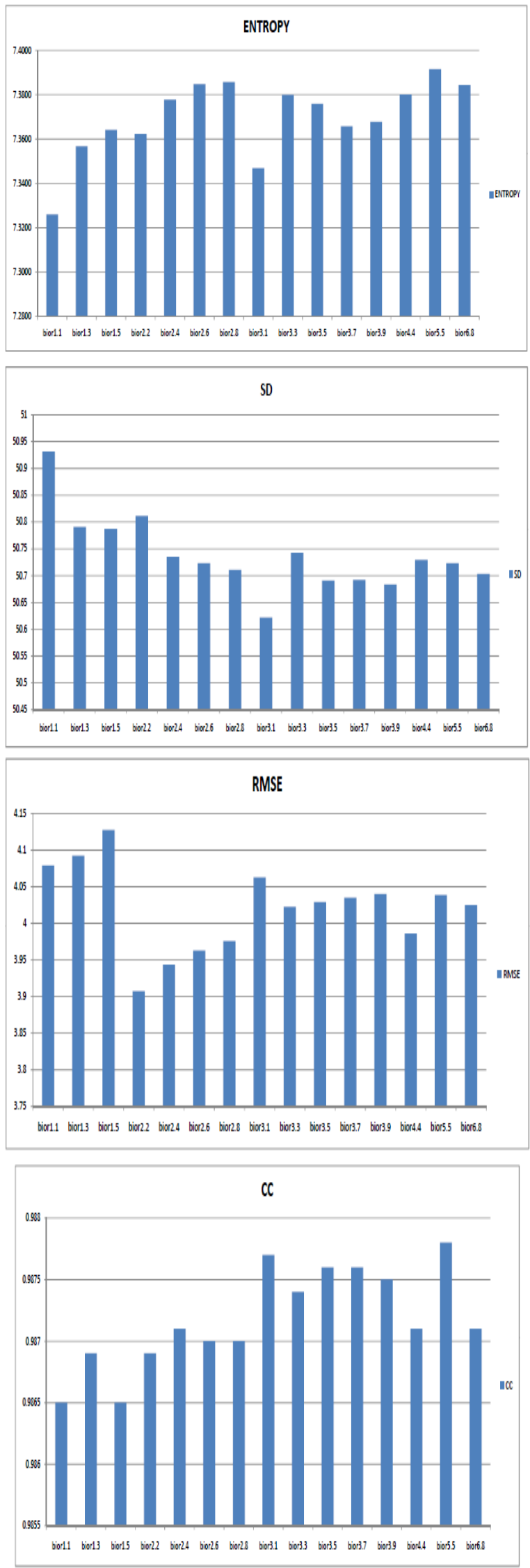

Fig 5: Graphical Representation of Performance Parameters for Biorthogonal Wavelets 


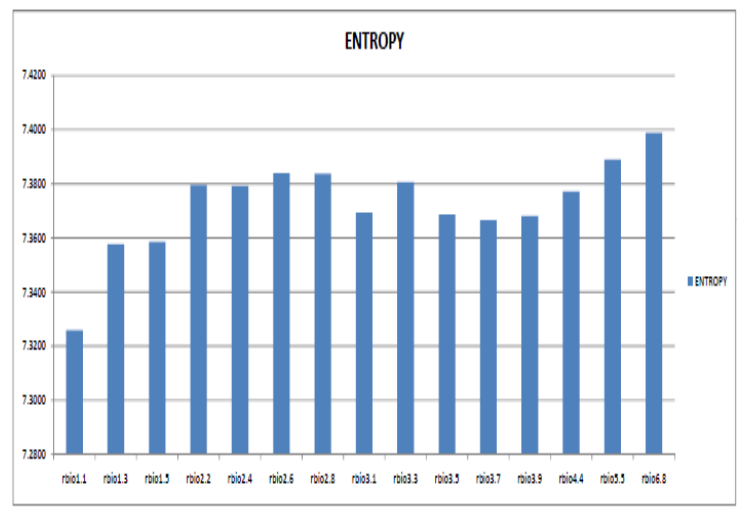

SD

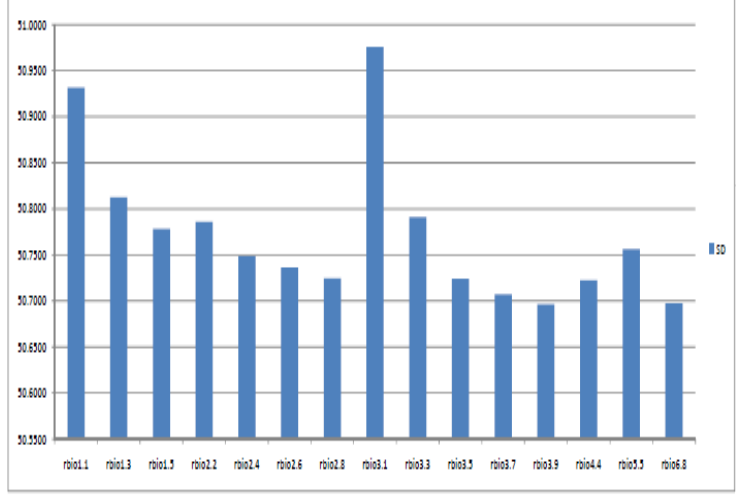

RMSE

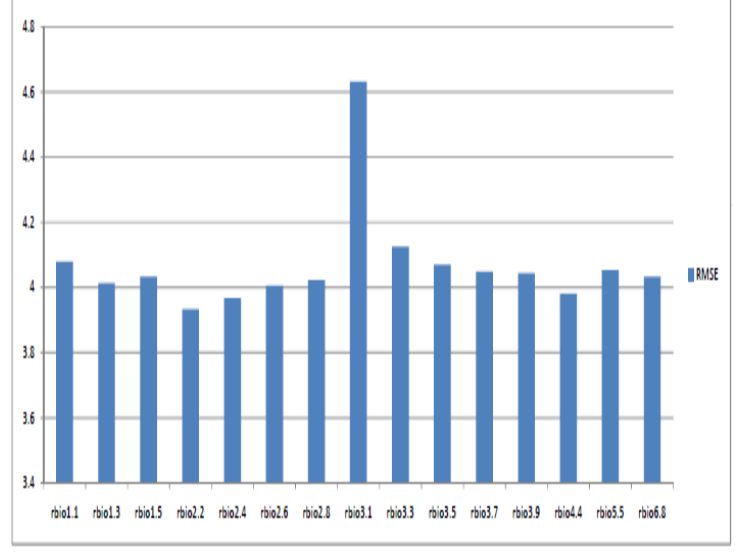

cC

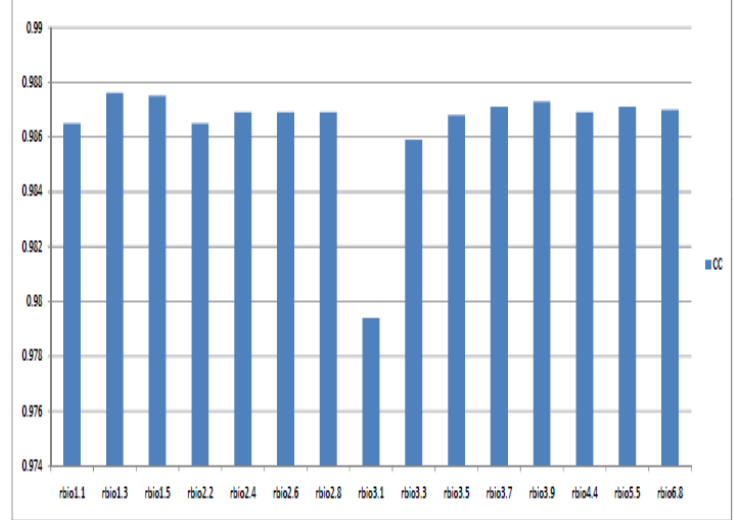

Fig 6: Graphical Representation of Performance Parameters for Reverse Biorthogonal Wavelets
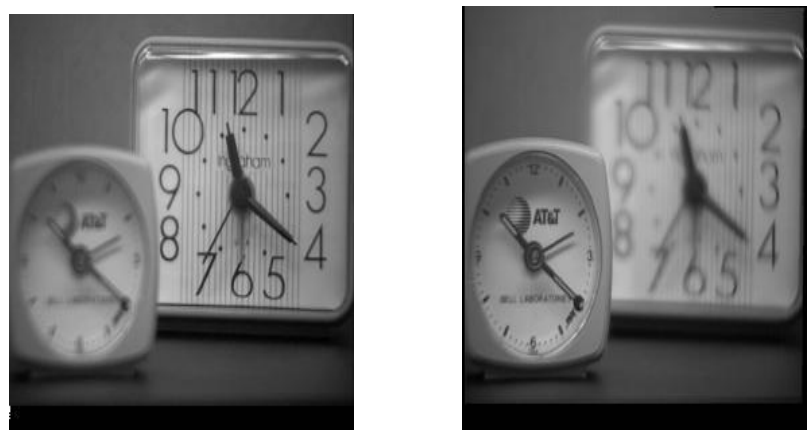

Fig 7: Source Images (Registered Multi-Focus Gray Scale)

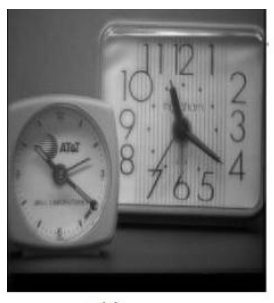

(a)

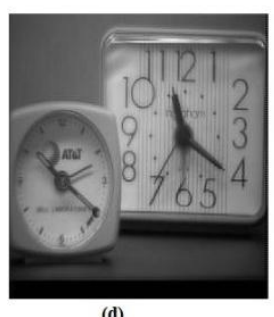

(d)

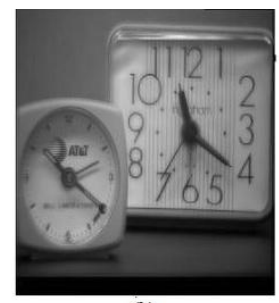

(b)

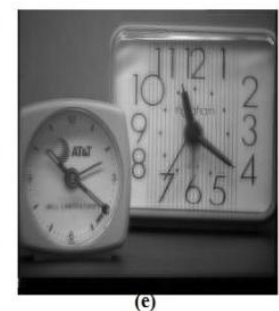

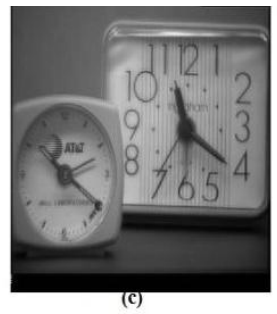

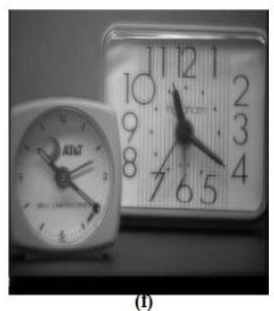

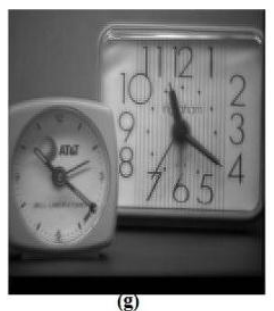

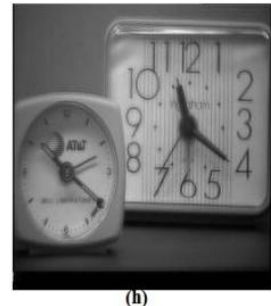

Figure 8: The fused images obtained using source images in Figure 7, with the wavelets (a) biorthognal2.2, (b) biorthogonal5.5, (c) coieflet1, (d) db2 or Haar, (e) daubechies20, (f) discrete Meyer, (g) reverse biorthogonal3.1, (h) symlet18 wavelets respectively.

\section{SUMMARY AND CONCLUSIONS}

With the above statistical analysis, we can conclude that the biorthogonal wavelet family i.e., biorthogonal and reverse biorthogonal wavelets are better suited for multi focus gray scale image fusion. This study can be improvised by carrying out the analysis for multi sensor and for color images as well. More accurate results can be obtained if the reference image of the scene is available which is not possible in most of the real time processing. Also usage of well defined masks such as prewitt instead of uniform mask in masking stage makes the analysis more sophisticated. Thus, the analysis is a better approach for selecting a proper wavelet in real time image processing applications. 


\section{REFERENCES}

[1]. Wang W., Shui P., and Song G., "Multi focus image fusion in wavelet domain", International Conference on Machine Learning and Cybernetics, November 2003, pp. 2887-2890.

[2]. Li S., Kwok J.T., Wang Y., "Combination of images with diverse focuses using the spatial frequency", Information Fusion, 2001, pp. 169-176.

[3]. Borwonwatanadelok P., Purahong S., Udomhunsakul S., "Selection of Wavelet Filters for Panoramic Dental X-Ray Image Compression", ICECT, 2009, pp. 237-241.

[4]. Jaruwan Toontham, Wirat Rattanapitak and Somkait Udomhunsakul, "Comparative Efficiency of Wavelet Filters for Multi-focus Color Image Fusion", in 2nd International Conference on Education Technology and Computer (ICETC), 2010, pp. V5-87 - V5-91.

[5]. Rafael C. Gonzalez, "Digital Image Processing", Prentice Hall publication, $3^{\text {rd }}$ edition, 2008.

[6]. Muhammad Hassan Arif, Syed Sqlain Shah, "Block Level Multi-Focus Image Fusion using Wavelet Transform", International Conference on Signal Acquisition and Processing, ICSAP 2009, pp. 213-216.

[7]. Dr. -Ing. Michael Heizmann, "Image Fusion Tutorial," in IEEE International Conference on Multi sensor Fusion and Integration for Intelligent Systems, Heidelberg, 2006.

[8]. Mallat, S.G., "A Wavelet Tour of Signal Processing", Academic Press, San Diego, second edition, 1999.

[9]. D. Lee Fugal, "Conceptual wavelets in digital signal processing”, Space \& Signals Technical publishing, 2009.

\section{BIOGRAPHIES}

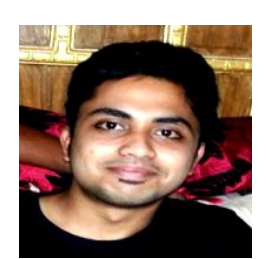

Design.

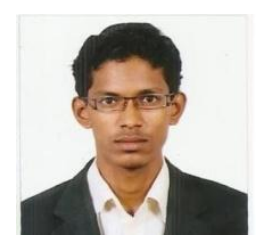

processing

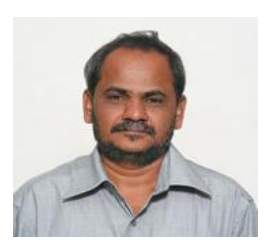
Dr.Suryakanth.V.Gangashetty received his Ph.D. from IIT (Madras). He is working as the Asst. Professor in the Languages and Technologies Research Centre (LTRC), IIIT- Hyderabad. His research interests include Speech processing, Image processing and Neural Networks.

Shaik Mohammed Waseem received the B.E (ECE) degree from Osmania University, Hyderabad in 2012. He is pursuing M. Tech (VLSI) from GRIET (JNTUH). His research interests include Image Processing, Design for Fault Tolerant Systems and Digital System

K. Mahammad Imran received the B.E (ECE) degree from Osmania University, Hyderabad in 2012 and he is pursuing M. E. (CESP) from VCE (O.U). His research interests include Image Processing, Cryptography and Speech

.

.

